\title{
European framework for tuberculosis control and elimination in countries with a low incidence
}

\author{
Recommendations of the World Health Organization (WHO), International Union Against \\ Tuberculosis and Lung Disease (IUATLD) and Royal Netherlands Tuberculosis \\ Association (KNCV) Working Group \\ J.F. Broekmans*, G.B. Migliori", H.L. Rieder ${ }^{\mp}$, J. Lees ${ }^{+}$, P. Ruutu ${ }^{\S}$, R. Loddenkemper ${ }^{f}$, \\ M.C. Raviglione**
}

European framework for tuberculosis control and elimination in countries with a low incidence. J.F. Broekmans, G.B. Migliori, H.L. Rieder, J. Lees, P. Ruutu, R. Loddenkemper, M.C. Raviglione. (C) ERS Journals Ltd 2002.

ABSTRACT: As countries approach the elimination phase of tuberculosis, specific problems and challenges emerge, due to the steadily declining incidence in the native population, the gradually increasing importance of the importation of latent tuberculosis infection and tuberculosis from other countries and the emergence of groups at particularly high risk of tuberculosis.

Therefore, a Working Group of the World Health Organization (WHO), the International Union Against Tuberculosis and Lung Disease (IUATLD) and the Royal Netherlands Tuberculosis Association (KNCV) have developed a new framework for low incidence countries based on concepts and definitions consistent with those of previous recommendations from WHO/IUATLD Working Groups.

In low-incidence countries, a broader spectrum of interventions is available and feasible, including: 1) a general approach to tuberculosis which ensures rapid detection and treatment of all the cases and prevention of unnecessary deaths; 2) an overall control strategy aimed at reducing the incidence of tuberculosis infection (risk-group management and prevention of transmission of infection in institutional settings) and 3) a tuberculosis elimination strategy aimed at reducing the prevalence of tuberculosis infection (outbreak management and provision of preventive therapy for specified groups and individuals).

Government and private sector commitment towards elimination, effective case detection among symptomatic individuals together with active case finding in special groups, standard treatment of disease and infection, access to tuberculosis diagnostic and treatment services, prevention (e.g. through screening and bacille Calmette-Guéria immunization in specified groups), surveillance and treatment outcome monitoring are prerequisites to implementing the policy package recommended in this new framework document.

Eur Respir J 2002; 19: 765-775.

The World Health Organization Framework for effective tuberculosis control and the need for a European Framework

In 1994 the World Health Organization (WHO) published its "Framework for Effective Tuberculosis Control", summarizing the strategy, control policy package and key technical operations of a national tuberculosis programme in countries with a high incidence of tuberculosis [1]. This "WHO framework" document encapsulates the essential elements of the WHO recommended strategy of tuberculosis control (DOTS strategy) [2, 3]. These are: political commitment to tuberculosis control; diagnosis based on
*Royal Netherlands Tuberculosis Association, The Hague, the Netherlands. ${ }^{\#}$ World Health Organization Collaborating Centre for Control of Tuberculosis and Lung Diseases in Europe, Fondazione Salvatore Maugeri, Clinica del Lavoro e della Riabilitazione, Care and Research Institute, Dept. Pneumonology, Tradate, Italy. "Tuberculosis Division of the International Union Against Tuberculosis and Lung Disease, Paris, France. ${ }^{+}$Dept of Health, London, UK. ${ }^{\S}$ National Public Health Institute, Helsinki, Finland. ${ }^{f}$ German Central Committee against Tuberculosis, Berlin, Germany. ${ }^{* *}$ Communicable Disease Programme, World Health Organization, Geneva, Switzerland.

Correspondence: G.B. Migliori, WHO Collaborating Centre for Control of Tuberculosis and Lung Diseases, Fondazione Salvatore Maugeri, Clinica del Lavoro e della Riabilitazione, Care and Research Institute, via Roncaccio 16, 21049, Tradate (VA), Italy. Fax: 390331829402

E-mail: gbmigliori@fsm.it

Keywords: Control, elimination, Europe, new framework, tuberculosis

Received: July 192001

Accepted after revision October 27 2001 bacteriology (sputum smear microscopy) and casefinding among symptomatic patients presenting to health services; standardized short-course chemotherapy provided under proper case-management conditions, including directly observed therapy; the provision of a regular supply of essential antituberculosis medications; the establishment and maintenance of a recording and reporting system with evaluation of treatment outcome $[4,5]$.

This document has contributed greatly to international consensus on what the prime focus of any national tuberculosis control programme should be: the prompt identification and documented cure of infectious cases $[4,6]$, allowing a reduction of the 
period of transmissibility of infection in the community [7] and a reduction in the risk of emergence of drug resistance [8].

The WHO framework [1] was designed for countries with a high incidence of tuberculosis. It is therefore, not sufficiently comprehensive for lowincidence countries in Europe, as it fails to take into account the technical sophistication and the resources at the disposal of these countries that allow a much more aggressive approach. The existing framework document also addresses the most important elements of tuberculosis control but excludes components necessary when embarking on an elimination strategy [9].

Up to now, no policy document has existed summarizing the essential elements of tuberculosis control in low-incidence countries, those industrialized countries of Europe that have already achieved a low incidence of the disease through the consistent application of existing technologies.

For this reason WHO, the International Union Against Tuberculosis and Lung Disease (IUATLD), and the Royal Netherlands Tuberculosis Association (KNCV) have jointly organized a series of workshops in Wolfheze, the Netherlands, since 1990. These have been aimed at reorienting tuberculosis control in Europe with the help of both tuberculosis-control experts and representatives of ministries of health $[9,10]$.

At the third European Workshop on Tuberculosis Control in Low Prevalence Countries (Wolfheze, 1997) it was proposed to explore the need and feasibility of developing a framework document for countries with a low incidence including those approaching the elimination phase of the disease [9]. It has been estimated that, without additional efforts, the elimination phase may still take up to 50-60 yrs until the actual point of elimination in these countries will be reached [9].

For this reason, it was felt that the low incidence countries in Europe needed a framework adjusted to achieve this. This framework should still be compatible with the global strategy for tuberculosis control advocated by WHO.

The European framework document presented here is intended mainly to: 1) alert and strengthen the political commitment of governments, and, specifically, of Ministries of Health in Europe to the changes required in policy setting and prioritization of activities; 2) encourage national tuberculosis control authorities and professional societies to incorporate elements of the framework into their efforts, adopting those appropriate to the local epidemiological and socioeconomical situation; 3) support educational programmes for medical, public health, nursing and laboratory workers pointing out the specific requirements of tuberculosis control in the elimination phase of tuberculosis.

\section{Definitions}

To allow for a common understanding, the following working definitions have been used in this document. Some have been defined in earlier documents, others are new and address specific issues raised in this European framework. 1) Latent infection. A latent infection with Mycobacterium tuberculosis complex (or "latent tuberculosis infection") is a subclinical infection with tubercle bacilli without clinical, bacteriological or radiological signs or symptoms of manifest disease [9, 11]. Typically this is an individual who has a positive tuberculin test and normal chest radiography. They may be a known contact of a previous case of tuberculosis. 2) Tuberculosis. Tuberculosis is defined as the clinically, bacteriologically and/or radiographically manifest disease [9]. 3) Low tuberculosis incidence countries. Low tuberculosis incidence countries have been defined as those with a crude case notification rate $<10$ (all cases) per 100,000 inhabitants and declining [9]. For the purposes of this Framework the definition has been extended to include all countries in Europe with a crude notification rate $<20$ per 100,000 population. 3) Tuberculosis elimination. Tuberculosis elimination is the point at which less than one infectious (sputum smear positive) case per 1,000,000 inhabitants emerges annually in the general population [9]. 4) Tuberculosis control strategies. Tuberculosis control strategies aim to reduce the incidence of new infections with $M$. tuberculosis complex by identifying sources of infection as rapidly as possible and rendering them noninfectious through curative treatment. 5) Tuberculosis elimination strategies. Tuberculosis elimination strategies include additional elements to reduce the prevalence of latent tuberculosis infection, such as preventive therapy for persons with an increased risk of progression from latent infection to overt clinical tuberculosis. 6) Preventive therapy. Preventive therapy is the treatment of latent tuberculosis infection to reduce the risk of progression to overt clinical disease [9]. 7) A risk factor for tuberculosis. A risk factor for tuberculosis is the presence of a factor in a person with latent tuberculosis infection that increases the risk of progression to disease, compared with the risk of a person without such a condition [12]. 8) High-risk groups. High-risk groups are those population segments at an increased risk of exposure to tuberculosis infection (arbitrarily, those with a notification rate of $>100$ cases per 100,000 population [9]). Some countries may prefer to consider the relative rather than the absolute risk in these groups. 9) Definite cases of tuberculosis. Definite cases of tuberculosis are those with culture confirmed disease due to $M$. tuberculosis complex [6]. Active case-finding is the deliberate search for tuberculosus disease or infection by means of clinical and radiographical examination, supplemented by tuberculin skin testing [9]. Case-finding among symptomatic individuals presenting to health services relies on patients with symptoms taking the initiative to attend health services. 10) Cured. A definite case has been defined as cured if the patient has completed the prescribed regimen and there is, at least once, a documented negative culture during the continuation phase of treatment. 11) Treatment completed. A case where the bacteriological evidence (negative culture) is not available, the case is defined as treatment 


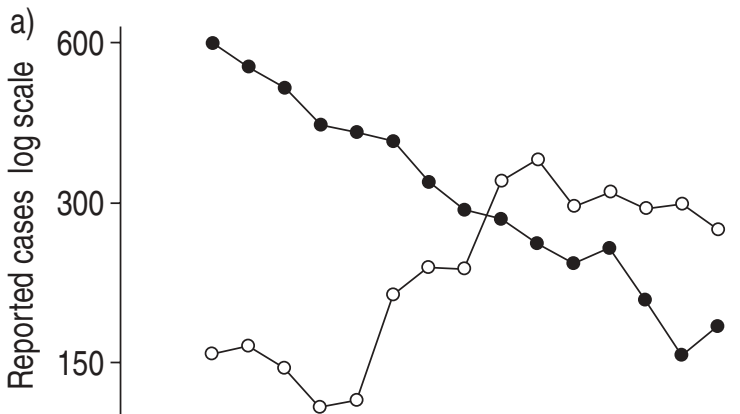

1982198419861988199019921994199619982000

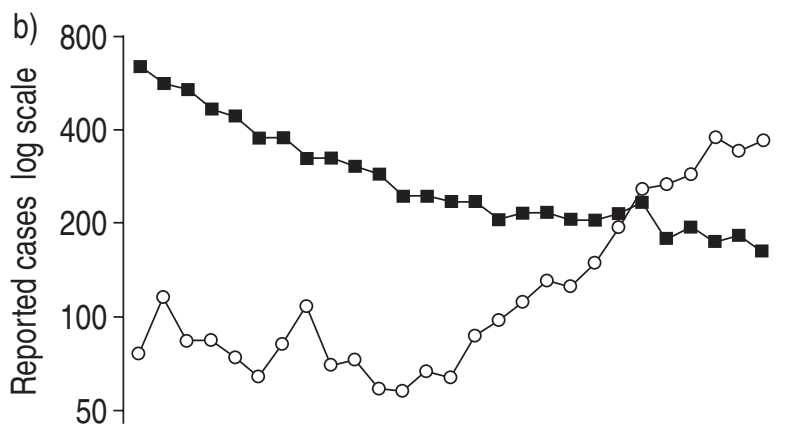

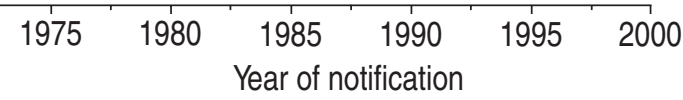

Fig. 1.-a) Reported tuberculosis cases in Sweden by country of birth, 1984-1996. b) Reported tuberculosis cases in Denmark by country of birth. $\bigcirc$ : born abroad; $\bullet$ : born in Sweden (modified from [13] using data from [14]); $\mathbf{0}$ : born in Denmark. Modified from [15] (T. Lillebaek, Statens Serum Institut, Copenhagen, Denmark, personal communication).

completed. 12) Treatment success. Treatment success is the sum of cases whose final outcome is cured or treatment completed. 13) Treatment failure. A treatment failure is a case who fails to achieve bacteriological conversion within 5 months after starting treatment, or becomes culture positive again after previous conversion. 14) Death. Death means a case who died of any cause during treatment. 15) Treatment interrupted (default). Treatment interrupted

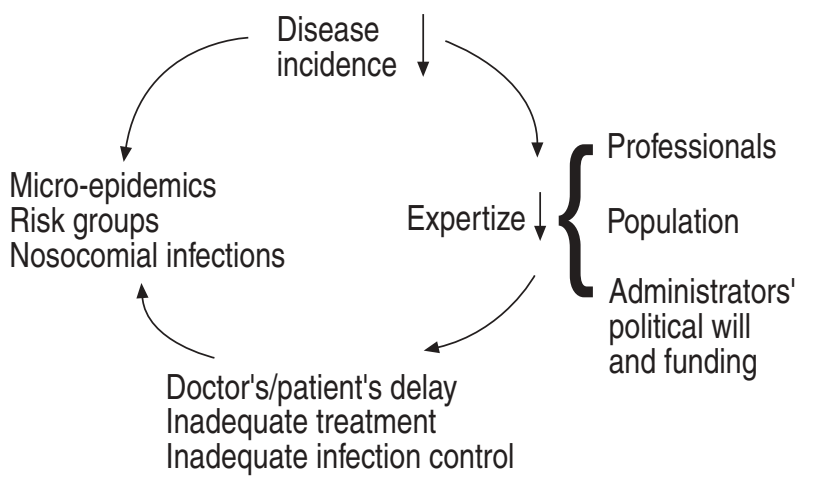

Fig. 2.-Problems and challenges in tuberculosis control and elimination. is a case in which treatment was interrupted for $>2$ months or the standard 6-month regimen was not completed within 9 months. 16) Transfer out. A case of tuberculosis transferred to another unit with the agreement of the treating physicians has been defined as transfer out [4].

While the six outcome categories must be respected, further stratification might be useful, e.g., death from and death with tuberculosis. Where drugsusceptibility testing allows early and reliable identification of multidrug-resistant strains and treatment with second-line drugs is commenced accordingly, the outcome from the first regimen must be defined as a failure at the point of the change in the treatment regimen. Obviously, such a patient must be reregistered and enters a new cohort to allow separate outcome assessment.

\section{Context: new challenges for tuberculosis control in Europe}

Most low-incidence industrialized countries are confronted with very specific problems and challenges as a result of the successful shift from high to low incidence over the past 50 yrs. These specific problems and challenges are a direct consequence of: the steadily declining disease incidence in the native population; the gradually increasing relative and absolute importance of the importation of latent tuberculosis infection and tuberculosis from other countries (figs. 1a, b, 2 and 3) (V. Romanus, Swedish Institute for Infectious Disease Control, Solna, Sweden, personal communication) $[13,15,16]$; the emergence of groups at particularly high risk of tuberculosis (e.g. human immunodeficiency virus (HIV)infected patients, homeless persons, prisoners in certain settings, etc.); the importation of drug-resistant and, particularly, multidrug-resistant $M$. tuberculosis from eastern European countries (i.e. strains resistant to at least isoniazid and rifampicin) $[17,19]$. Table 1 summarizes epidemiological indicators and available information on drug resistance in Europe.

In most European countries, tuberculosis morbidity among the native population has declined dramatically in the twentieth century [12], yet notification data indicate that the regular decline previously observed slowed down or was halted in several low-incidence countries in Europe in the 1990s [18, 20].

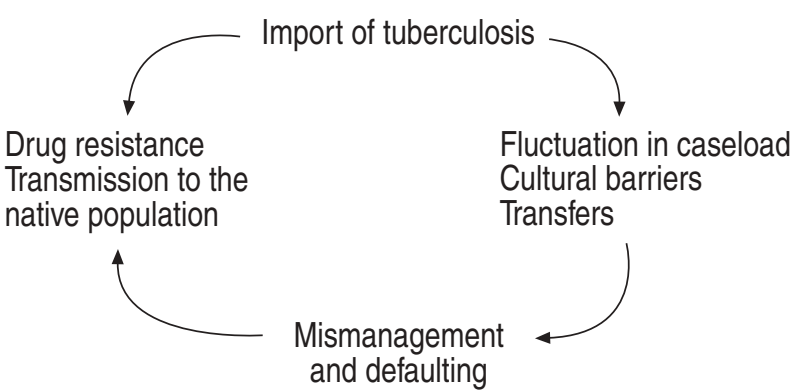

Fig. 3.-Problems and challenges in tuberculosis control and elimination. 
The proportion of immigrants among tuberculosis cases notified in 1998 exceeded 50\% in Andorra, Denmark, Israel, Luxembourg, Norway, Sweden, Switzerland (notified as foreign born) and the Netherlands (notified as foreign citizen) [16]. This phenomenon is particularly highlighted by increased international migration from high- to low-incidence countries [21].

Segments of the population at high risk of HIV infection (e.g. commercial sex workers, injected drug users, prisoners) frequently have higher tuberculosis incidence rates than the general population.

As tuberculosis declines in a community, groups at particularly high risk become more visible. This provides an opportunity for targeted intervention. New challenges for treatment and management of patients harbouring multidrug-resistant strains are emerging and pose substantial constraints on infrastructure, policy, and resources [17, 19, 22].

The global dynamics of the tuberculosis epidemic mean that a common approach to tuberculosis control policies and activities in the European countries at low incidence of tuberculosis will be more likely to hasten the elimination of tuberculosis from Europe [9].

\section{Aims of the elimination strategy}

Formulation of an elimination strategy requires consideration of the dynamics of tuberculosis infection in the population. At the centre of these dynamics are cases of subclinical, latent infection with $M$. tuberculosis. This has been recognized for $>30$ yrs [23]. Tuberculosis control and elimination strategies must aim at diminishing the incidence and prevalence of latent infection to reduce the pool of those with tuberculosis infection from which future cases of tuberculosis will emanate. This can be accomplished using two different approaches, the first being to reduce the incidence of new tuberculosis infection, the second to reduce its prevalence.

In the low-tuberculosis incidence countries of Europe, the oldest generations of the indigenous population have the highest prevalence of latent tuberculosis infection [24]. This is because they were born at a time when the risk of tuberculosis infection was high and/or they have had a long cumulative probability of acquiring infection. In contrast, the youngest generations have a very low prevalence and risk of tuberculosis infection. With the passage of time, as long as the risk of infection in the general population continues to decline, each generation will be replaced by a generation with less and less infection. To ensure that this remains the case, it is essential to minimize the risk of new generations becoming infected through early identification and cure of newly emerging transmitters of infection, i.e. infectious cases. Furthermore, should they become infected, their infection must be prevented from progressing to overt disease. This combined approach is recommended so that progress towards elimination of tuberculosis from Europe can be hastened.

Table 1. - Summary of surveillance and resistance data

\begin{tabular}{|c|c|c|c|c|c|c|c|}
\hline Country & $\begin{array}{c}\text { Year } \\
\text { notification } \\
\text { data }\end{array}$ & $\begin{array}{c}\text { Overall incidence } \\
\text { notified cases } \\
\text { per } 100,000 \\
\text { population }\end{array}$ & $\begin{array}{l}{ }^{\top,+} \text { Incidence of } \\
\text { notified definite } \\
\text { cases Pulm } C^{+} \text {per } \\
100,000 \text { population }\end{array}$ & $\begin{array}{l}\text { Foreign } \\
\text { born } \%\end{array}$ & $\begin{array}{c}\text { Year } \\
\text { resistance } \\
\text { data }^{\top, \S}\end{array}$ & $\begin{array}{l}\text { Any } \\
\mathrm{H} \%\end{array}$ & $\begin{array}{l}\text { Any } \\
\text { MDR \% }\end{array}$ \\
\hline Czech Republic & 1998 & 17.6 & 9.2 & 6 & 1999 & $3.2^{f, \# \#}$ & $1.6^{f, \# \#}$ \\
\hline Denmark & 1998 & 10.0 & 8.4 & 65 & 1998 & $6.1^{\# \#}$ & $0.5^{\# \#}$ \\
\hline England \& Wales & 1998 & & & & 1997 & $5.0^{\# \#}$ & $0.8^{\# \#}$ \\
\hline Northern Ireland & 1998 & & & & 1997 & $2.4^{\# \#}$ & $0.0^{\# \#}$ \\
\hline Scotland & 1998 & $10.5^{f f}$ & $6.3^{f f}$ & $48^{f f}$ & 1997 & $3.7^{\# \#}$ & $0.3^{\# \#}$ \\
\hline Estonia & 1998 & 57.2 & 37.5 & 14 & 1998 & $26.0^{\# \#}$ & $14.1^{\# \#}$ \\
\hline Finland & 1998 & 12.2 & 6.6 & 8 & 1997 & $4.6^{\# \#}$ & $0.0^{\# \#}$ \\
\hline France & 1998 & 11.0 & 2.8 & $24^{++}$ & 1997 & 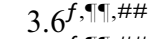 & $0.0^{f, \boldsymbol{\uparrow} \uparrow, \# \#}$ \\
\hline Germany & 1998 & 12.7 & 7.3 & $32^{++}$ & 1998 & 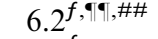 & $1.3^{f, \oplus \uparrow, \# \#}$ \\
\hline Italy & 1998 & 8.4 & 3.9 & $17^{++}$ & $1998 / 1999$ & $5.6^{f}$ & $1.2^{f}$ \\
\hline Latvia & 1998 & 90.0 & 51.8 & 3 & 1998 & $28.1^{\# \#}$ & $9.0^{\# \#}$ \\
\hline Netherlands & 1998 & 8.6 & 4.4 & $60^{++}$ & 1996 & $6.3^{\# \#}$ & $0.6^{\# \#}$ \\
\hline Norway & 1998 & 5.5 & 4 & 53 & 1996 & $8.0^{\# \#}$ & $2.2^{\# \#}$ \\
\hline Poland & 1998 & 34.4 & 19.4 & & 1997 & $2.7^{f, \# \#}$ & $0.6^{f, \# \#}$ \\
\hline $\begin{array}{l}\text { Russian Federation } \\
\text { (Tomsk Oblast) }\end{array}$ & 1998 & & & & 1999 & $19.4^{f, \# \#}$ & $6.5^{f, \# \#}$ \\
\hline $\begin{array}{l}\text { Russian Federation } \\
\text { (Ivanovo Oblast) }\end{array}$ & 1998 & $82.7^{\# \# \#}$ & & & 1998 & $22.1^{\# \#}$ & $9.0^{\# \#}$ \\
\hline Slovakia & 1998 & 23.8 & 13.7 & 0 & 1998 & $2.0^{f, \# \#}$ & $0.3^{f, \# \#}$ \\
\hline Slovenia & 1998 & 22.5 & 17.4 & 0 & 1997 & $1.0^{\# \#}$ & $0.7^{\# \#}$ \\
\hline Spain & 1998 & 22.9 & 6.5 & 1 & 1998 & $2.2^{f, \uparrow \uparrow, \S \S}$ & $0.3^{f, \uparrow \uparrow, \S \S}$ \\
\hline Sweden & 1998 & 5.0 & 4.1 & 60 & 1997 & $5.6^{\# \#}$ & $0.6^{\# \#}$ \\
\hline Switzerland & 1998 & 10.3 & 8.3 & 55 & 1997 & $2.8^{\# \#}$ & $0.0^{\# \#}$ \\
\hline
\end{tabular}

Pulm $\mathrm{C}^{+}$: pulmonary culture positive $\mathrm{C}^{+} ; \mathrm{H}$ : isoniazid; MDR: multidrug-resistance. ${ }^{\#}$ : only countries providing resistance data stratified for previous treatment status were included; ${ }^{\uparrow}$ : derived from [16]; ${ }^{+}$: derived from [18]; ${ }^{\text {: }}$. derived from [17]; ${ }^{f}$ : completed survey; ${ }^{\# \#}$ : all cases or random selection; ${ }^{\uparrow \uparrow}$ : sentinel sites; ${ }^{++}$: foreign citizen; ${ }^{\$}$ : Barcelona city only; ${ }^{f f}$ : combined values for England and Wales, Northern Ireland and Scotland; ${ }^{\# \#}$ : combined values for Tomsk Oblast and Ivanovo Oblast. 


\section{Approach to control and elimination of tuberculosis}

The basic tuberculosis control strategy in lowincidence countries aims at minimizing transmission of tuberculosis by maintaining high case-finding and cure rates, especially among potentially infectious, bacteriologically confirmed cases. In this respect the control strategy is that advocated by WHO in the 1994 "Framework for Effective Tuberculosis Control" document [1].

The most important additional elements of a more aggressive approach are. 1) Ensuring early detection of tuberculosis patients and their treatment until cure and preventing avoidable death from tuberculosis. 2) Reducing the incidence of infection by risk group management and prevention of transmission of infection in institutional settings. 3) Reducing the prevalence of tuberculosis infection through outbreak management and provision of preventive therapy for specified groups and individuals.

Ensuring treatment for all tuberculosis patients and preventing avoidable death

The clinician's duty is to ensure that any patient with tuberculosis is promptly diagnosed and treated in order to reduce human suffering and avoidable death. Despite availability of diagnostic tools and efficacious treatment, some patients in Europe continue to remain undiagnosed until death from or with tuberculosis $[14,25,26]$. The decline in disease incidence adversely affects the clinical index of suspicion, and points to the need for continuing professional education in the field.

\section{Reducing the incidence of tuberculosis infection}

The incidence of tuberculosis infection in the community is most effectively reduced by identification of potential sources of infection in the community at the earliest possible time and interruption of the chain of transmission.

Risk-group management. Although there are significant differences between countries, a large fraction of cases in Europe arise from groups with a high prevalence of latent tuberculosis infection (and of active disease). These include immigrants from countries with a high incidence of tuberculosis $[16,21$, 27-29], ethnic minorities [30, 31], residents of jails and prisons [32, 33], hospital wards [34-37], nursing homes and homeless shelters [38-40], the elderly [10], and household contacts of recent tuberculosis cases. Riskgroup management involves active rather than solely opportunistic case-finding, aimed at detecting both those with active disease and with latent infection. These activities need to be in concert with provision of effective treatment, and preventive therapy as appropriate.

Prevention of the transmission of infection in institutional settings. Transmission of tuberculosis infection in institutional settings such as jails and prisons, hospitals, nursing homes/long-term residential homes for the elderly and shelters for the homeless and for new immigrants, (both within the institutionalized population and to the staff), makes infection prevention in institutional settings a public health priority in Europe. Administrative measures like active screening by chest radiography and tuberculin testing among residents and staff may be considered.

\section{Reducing the prevalence of tuberculosis infection}

The tuberculosis elimination strategy in low incidence countries aims at reducing the prevalence of latent infection with $M$. tuberculosis particularly among those at high risk of progression to manifest disease. Such individuals include recently infected contacts of cases [9], HIV infected individuals [34-36, 41] and persons with fibrotic lesions from previously untreated but spontaneously healed tuberculosis [42].

Management of outbreaks. An important group of people with recent infection are persons associated with a common source case in a recognized outbreak of tuberculosis. In these circumstances the source case has been demonstrated to be infectious to others. Outbreak management requires the identification of people with probable recent transmission (starting with close household contacts or equivalent but extending the circle if necessary according to the "stone in the pond" principle) [43], followed by adequate treatment and preventive chemotherapy for those found to be infected [44]. Identifying related cases using (deoxyribonucleic acid) DNA fingerprint technology opens the way to identify transmitters and to improve control by identifying "cluster epidemics" $[45,46]$. Furthermore, this technique allows study of which tuberculosis cases, within the native population, are more likely due to reactivation of remotelyacquired infection or to recent transmission $[10,16$, 27, 28, 34-36, 47].

Provision of preventive therapy for specific groups and individuals. It has been demonstrated in numerous prospective clinical trials that preventive chemotherapy with isoniazid for a 1-yr duration is efficacious in reducing the risk of tuberculosis among persons with latent infection [42, 44, 48-54].

\section{Prerequisites to implement the European framework}

Maintenance of effective tuberculosis control in low incidence countries and achievement of elimination will depend on the implementation of a tuberculosis policy package which includes. 1) Government and private sector commitment towards control and elimination. 2) Case detection through case-finding among symptomatic individuals presenting at health services and active case-finding in special groups. 3) Access to tuberculosis diagnostic and treatment services. 4) Standard approach to treatment of disease 
and infection. 5) Surveillance and treatment outcome monitoring.

\section{Government and private-sector commitment towards elimination}

Efficient tuberculosis control and ultimate elimination will not be possible without government commitment. Government commitment is demonstrated by: provision of the necessary basic infrastructure (in terms of funding, human resources and facilities) to allow tuberculosis care and control; effective technical leadership at a national level; adequate legal framework in support of specific control and elimination activities.

With these tools, governments should ensure, in collaboration with the private sector, the development of a coherent, consensus-based national tuberculosis control and elimination policy, including: maintaining high and timely case-finding rates and high treatmentsuccess rates; risk-group management; outbreak management; enhanced infection prevention in institutional settings; provision of preventive therapy.

Guidelines for the implementation of risk-group management, outbreak management, infection prevention in institutional settings and provision of preventive therapy should be developed, based on the national epidemiology and cost-effectiveness evaluation. Guidelines for occupational protection should also be produced and distributed, and their application monitored.

The key technical operations to sustain and implement the framework include: 1) National schemes for the control and elimination of tuberculosis; 2) national tuberculosis control policy; 3) national tuberculosis network; 4) legal framework; 5) humanresources development; 6) health education; 7) research; 8) international and European collaboration.

National schemes for the control and elimination of tuberculosis. A national scheme (or a clearly identified "programme", depending on the choice by the government) for the control and elimination of tuberculosis is necessary to ensure tuberculosis control even in countries with a low prevalence. With the decline in incidence of tuberculosis, the previous "vertical" approach towards tuberculosis control is no longer sustainable. In the majority of European countries the old National Tuberculosis Programmes disappeared during the 1970 s to be replaced by new integrated approaches. The key activities should be planned, coordinated, supervised and evaluated by a core group of experienced professionals. The decline in tuberculosis incidence has resulted in loss of expertize on tuberculosis management and control. Relevant expertize in tuberculosis management and control can be found in governmental as well as in nongovernmental agencies (including professional and scientific societies) [55]. Identification of the responsibilities of specific people for specific activities within the national team is recommended. Within the team, a balance among the different components of the control effort (surveillance, prevention, diagnosis, including the laboratory network, and treatment) should be ensured.

The (re-)establishment of a national scheme for the control and elimination of tuberculosis should include a central coordinator and a team of national experts to guide and support the network of health professionals and professional associations directly and indirectly involved in the local execution of tuberculosis control and elimination activities.

National tuberculosis control policy. As priorities are rapidly changing, the development of a system to establish and continuously update a consensusbased national tuberculosis control policy is crucial. Serious consideration should be given to the establishment of a "national tuberculosis policy committee" with adequate representation of all major stakeholders in tuberculosis control, such as representatives of organizations dealing with refugees and asylum seekers, HIV-infected patients, prisons etc. Such a committee should be composed in such a way as to finely balance the requirements of high-level expertize and practical experience as well as broadbased consensus. While the national scheme for tuberculosis control involves essentially technical units, the policy committee needs a balance of technical, political and administrative members. The committee should be composed of governmental agency managers as well as leading representatives of nongovernmental agencies and scientific societies.

In several European countries control and elimination activities are organized on a regional level. The actual implementation of the national tuberculosis control policy at regional level could be evaluated by the development of a quality assurance system complemented by regular external (if required multidisciplinary) audit. Professionals active in different regions or countries (from governmental and nongovernmental agencies) can act as external auditors. These national tuberculosis control and elimination policy guidelines are to be based on scientific evidence.

National tuberculosis network. (Re-)establishment and/ or maintenance of a national tuberculosis network in terms of funding, human resources and facilities is vital. Bacteriological laboratories and specialist nursing support are an integral part of this network. Public and private sectors should collaborate within the network. The network, identified and coordinated within the national scheme, is responsible for the different tuberculosis-control activities, based on the national tuberculosis control policy.

Legal framework. The legal framework is one expression of government commitment. A committed government supports tuberculosis control and elimination activities with appropriate legislation. A legal framework comprises laws, orders, circular letters and other different acts in different countries. A good legal framework should allow updating of policies in a flexible manner, in order to respond quickly to the changing priorities of tuberculosis control and elimination (e.g. a law requiring approval of a legislation/political body will require considerably 
more time for approval than a technical circular letter, needing the approval of a technical body only). Essential elements of the legal framework for European countries include compulsory notification of individual tuberculosis cases [6], free cost access to diagnostic and treatment services for all patients (including illegal immigrants) $[21,22,55]$, and limitations to the use of rifampicin in the open market [56].

In addition, the issues of screening programmes for special groups at risk and of protecting public health when an individual is not willing to cooperate (e.g. refusal to adhere to the prescribed treatment) should be addressed according to the different legislative bodies in the different countries.

Human-resources development. Adequate graduate and postgraduate education for staff involved directly (control officers, public-health nurses, chest physicians and bacteriologists) as well as indirectly (physicians and nurses involved in the patient care of asylum seekers, prisoners etc.) in tuberculosis control and elimination should be developed in collaboration with universities, training institutes, professional societies and other nongovernmental agencies, within the aims of the national programme and the framework of the national policy $[55,57]$. Adequate teaching at medical and nursing schools should include: the essential knowledge, skills and attitudes needed by different health professionals in provision of care, decision making, communication, community leadership and management; the educational strategy; development of practice guidelines; continuing education opportunities after formal training [57].

As the provision of a socially and culturally sensitive environment is essential to ensure rapid diagnosis and effective treatment of tuberculosis patients (immigrants in particular), contacts with community leaders should be made to ensure translation and support during case management from the first contact to the final cure.

Specific on-the-job training should be planned for nonmedical personnel (from charity organizations, religious groups, retired persons, volunteers) that can be involved on a voluntary basis in the provision of directly observed therapy.

Health education. Modern health-education material (brochures, videos etc.) should be developed to facilitate the execution of tuberculosis control and elimination activities. Leaders of foreign-born communities should collaborate in developing educational materials in the original language of the community. Culturally-adapted material is part of an overall approach aimed at identifying, designing and evaluating the tools for reliable communication between healthcare professionals, tuberculosis patients, their families, and their community. Tuberculosis managers should seek the help of social scientists for building and implementing such tools, and evaluating them [58]. The design, print and distribution of educational material for patients and medical staff requires the input of the national team of experts to ensure they are adequate for local and national needs.
Research. Operational and epidemiological research should address key constraints in the implementation of control and elimination policies and evaluate the impact of specific interventions and the introduction of new technologies and tools. Priorities include research projects which focus on the operational aspects of tuberculosis control. Examples include setting up of notification systems, including crossnotification with laboratories and surveillance of drug resistance, setting up of systems to monitor treatment results on a national scale, addressing how to ensure adherence to treatment in certain parts of the tuberculosis population, how to ensure preventive and treatment services for immigrants, how to document the outcome of screening activities, and how to optimize collaboration with other programmes such as national HIV control activities. The costeffectiveness of screening has rarely been evaluated and is an urgent issue to be addressed.

International and European collaboration. Tuberculosis is a global problem. High-incidence countries are facing enormous problems in controlling tuberculosis and are exporting tuberculosis cases (and infections) to low-incidence countries. Expertize in tuberculosis management and control can be maintained and increased in low-incidence countries by collaborating in tuberculosis-control programmes in high-incidence countries. Moreover, independent audit performed by European professionals as "peer review" both within and outside Europe may contribute to increasing expertize, improving programme monitoring and creating awareness of the need for a global approach to tuberculosis control. Tuberculosis elimination in Europe will not be reached without a coordinated global approach by low-incidence countries towards tuberculosis control in high-incidence countries. Surveillance to detect outbreaks on an international level using DNA-based typing results stored in data banks is an additional component of the European collaboration.

\section{Case detection through case-finding among symptomatic individuals presenting to health services and active case-finding in special groups}

As the incidence of tuberculosis is declining, prompt diagnosis of tuberculosis cases will require good quality laboratory services and sensitized professional and ancillary staff in the health service and elsewhere.

Although case-finding limited to symptomatic individuals presenting to health services, commonly considered the most cost-effective approach, remains the basis of the case-detection policy, a more aggressive approach in countries with low incidence of tuberculosis is justified. Active case-finding can be performed in special groups (clearly identified by the national team of experts) with an incidence of tuberculosis higher than that of the general population. Hopefully, the selection of the special groups is to be based on cost-effectiveness evaluation. Unfortunately, studies investigating cost-effectiveness of active screening are not yet available in Europe. 
Diagnosis and treatment outcome monitoring should be based on bacteriological confirmation wherever possible. The case definition of tuberculosis in Europe is based on culture [6]. Laboratories should use standard methods for drug susceptibility testing with a quality assurance programme including national and international proficiency testing [59]. Proficiency testing procedures should also be developed to maintain good standards in direct microscopy, particularly when the incidence of new sputum smear positive cases is declining. Similarly, quality control programmes should be designed for radiology and pathology (histology) services.

\section{Standard approach to treatment of disease and infection}

To maintain high cure rates, the main goal is to achieve completion of treatment using modern chemotherapy with standardized regimens. A 6-month regimen has been determined to be the most efficacious $[60,61]$. This regimen is appropriate in most countries in the elimination phase [22, 60-62]. However, the overall resistance situation and the nature of the most important risk groups in a country will influence the national recommendations for the first-line treatment regimen [63].

It is recommended that the treatment of multidrugresistant tuberculosis cases is based on drug susceptibility test results, including at least two, preferably three, drugs to which the organism is susceptible in an individualized regimen. Multidrug-resistant cases should be referred to specialist centres with: validated laboratory proficiency and biosafety measures as well as expertize in clinical management of drugresistant tuberculosis cases; availability of adequate methods to prevent transmission of resistant strains to patients and health staff (e.g. negative pressure rooms) [64]; intensive patient monitoring (with all therapy normally directly observed) during both the intensive and the continuation phase of treatment, in order to ensure treatment and early detection and management of adverse reactions [8, 22, 62].

A policy of directly observed therapy is recommended at least for patients whose adherence to treatment is in doubt. Directly observed therapy is recommended for all patients during the intensive phase of treatment [8].

A policy of preventive chemotherapy in selected patients, according to the principles and recommendations outlined in this document, is essential in European countries approaching the elimination phase. The regimen and the management strategy should be elaborated at the national level, and recommendations based on evidence from clinical trials [42, 44, 48-54, 65].

A review of bacille Calmette-Guéria (BCG) vaccination policy is necessary. Evidence of the effectiveness of BCG in protecting infants from disseminated and meningeal tuberculosis, and death from tuberculosis is overwhelming. The protective efficacy in other situations is much more variable. It is thus important to evaluate the cost-effectiveness of $\mathrm{BCG}$ vaccination programmes in low-incidence countries continuing its use, including an assessment of the frequency of adverse effects, and the need for selective BCG immunization programmes/policies in case universal vaccination is discontinued [66].

\section{Accessibility to tuberculosis diagnostic and treatment services}

Provision of healthcare in general and tuberculosis services in particular must take account of the fact that tuberculosis preferentially strikes the poorest segments of the population [31], and hence provide services that are either free of charge or covered by comprehensive insurance schemes. As an increasing proportion of tuberculosis cases emerge among foreign-born persons, culturally-sensitive services are essential if the elimination strategy is to succeed [10, 20, 58]. Furthermore, coordination between tuberculosis and HIV dedicated services is recommended from the national to the local level. To ensure the same quality of health care for all tuberculosis patients close collaboration among the civilian, military, and prison health services is necessary.

\section{Surveillance and treatment outcome monitoring}

Maintenance of a surveillance and monitoring system. The Wolfheze consensus documents "Surveillance of tuberculosis in Europe" [6], "Standardized tuberculosis treatment outcome monitoring in Europe" [4], and "Standardization of antituberculosis drug resistance surveillance in Europe" [59] provide the basic components for such surveillance and monitoring in low-incidence countries of Europe.

Surveillance and monitoring. The surveillance and monitoring of tuberculosis control activities should be based on the existing European consensus documents $[4,6,20,59]$. Surveillance must ensure that a minimum set of nine variables (date of starting treatment, place of residence, date of birth, sex, country of origin, site of disease, bacteriological status and history of previous antituberculosis treatment) is collected in a timely manner on all tuberculosis patients on an individual basis. Physicians' compulsory notifications should be supplemented by laboratory notifications and the two systems should be linked [6]. Treatment-outcome monitoring is based on six mutually exclusive categories (cure and treatment completion, the sum of which represents the treatment success, death, failure, treatment interruption and transfer out), evaluated by cohort analysis [4, 67].

The proportion of cases resistant to first-line drugs and of multidrug-resistant cases among incident cases should be evaluated routinely within surveillance activities, or, where not feasible, by means of representative surveys or sentinel studies [59, 68, 69]. As multidrug-resistant tuberculosis represents a threat to tuberculosis control, the prevalence of multidrug resistance at country level is a useful indicator of the 
performance of the treatment programme and for planning proper public health action, if necessary. In countries where drug-resistance surveillance is not routinely implemented, a national register of multidrug-resistant cases should be considered. The register should include all patients with at least one multidrug-resistant isolate within a given calendar year [59]. Additional pieces of information can be obtained through the link of this register with the tuberculosis notification system and/or by means of ad hoc questionnaires [59].

A set of indicators is necessary to assess the progress in tuberculosis control towards elimination at national level, and to allow international comparisons among different countries. Suggested indicators include: indicators of government commitment (e.g. availability of a national tuberculosis control policy); coverage of the policy (e.g. proportion of country implementing the national strategy); indicators of control performance (e.g. proportion of definite cases, proportion of definite pulmonary tuberculosis cases with successful outcome (cure and treatment completion), and proportion of tuberculosis cases with unsuccessful treatment outcomes (death, failure, treatment interruption), assessment of BCG coverage); indicators of the functioning of the surveillance system (e.g. time trends in tuberculosis notifications, for all and pulmonary cases); number of cultures and proportion of cultures positive for M. tuberculosis complex among all examinations requested for mycobacterial investigation, number of direct smear microscopy examinations and proportion of positive results; estimate of patient's and doctor's delay in diagnosis and treatment; prevalence of multidrug-resistant tuberculosis in new and retreatment tuberculosis cases.

Additional examples of input indicators include indicators of training, supervision, and other managerial aspects of tuberculosis control.

A reasonable target for low-incidence countries is to reduce the proportion of patients with a potentially bacteriologically unsuccessful outcome (failure, default, transfer) to $<10 \%$. In high-risk groups, the proposed targets are to screen $95 \%$ of the population at risk and to treat $95 \%$.

\section{Conclusions}

Low tuberculosis-incidence countries of Europe are committed to the elimination of tuberculosis [9]. This commitment requires a clear strategy and the technical capacity to implement it. This paper provides a framework to pursue better control and foster elimination of tuberculosis in European settings where incidence is low and resources are available. A balanced combination of traditional principles and innovative technologies is necessary to achieve this aim.
Members of the Working Group. P. Andersen (Denmark), T. Blöndal (Iceland), J.F. Broekmans (the Netherlands), D. Chemtob (Israel), P. Davies (UK), M. Diaz (Spain), B. Farruga (Malta), M. Forssbohm (Germany), O. Hamouda (Germany), P. Helbling (Switzerland), P. Jennings (Ireland), P. Kalina (Czech Republic), P. Kelly (Ireland), J.P. Klein (Austria), M. Kokki (Finland), F. Krejbich (Czech Republic), A. Infuso (EuroTB, France), C.S.B Lambregts-van Weezenbeek (the Netherlands), J. Leese (UK), T. Lillebaek (Denmark), R. Loddenkemper (Germany), D. Maher (WHO HQ, Geneva, Switzerland), G.B. Migliori (Italy), M.L. Moro (Italy), M.C. Raviglione (WHO HQ, Geneva, Switzerland), H.L. Rieder (IUATLD, Switzerland), V. Romanus (Sweden), P. Ruutu (Finland), H. Shang (Switzerland), B. Schmidgruber (Austria), M. Wanlin (Belgium), J.M. Watson (UK), J.P. Zellweger (Switzerland).

\section{References}

1. World Health Organization. WHO Tuberculosis Programme framework for effective tuberculosis control. World Health Organization Document WHO/TB/ 94.1: 1-7. World Health Oranization, Geneva, 1994.

2. World Health Organization. Tuberculosis handbook. World Health Organization Document WHO/TB/ 98.253: 1-222. World Health Oranization, Geneva, 1998.

3. Raviglione MC, Dye C, Schmidt S, Kochi A. Assessment of worldwide tuberculosis control. Lancet 1997; 350: 624-629.

4. Veen J, Raviglione M, Rieder HL, et al. Standardized tuberculosis treatment outcome monitoring in Europe. Recommendations of a Working Group of the World Health Organisation (WHO) and the European Region of the International Union Against Tuberculosis and Lung Disease (IUATLD) for uniform reporting by cohort analysis of treatment outcome in tuberculosis patients. Eur Respir J 1998; 12: 505-510.

5. Migliori GB, Ambrosetti M, Besozzi G, Casali L, Raviglione MC. Prospective multicentre study on the evaluation of antituberculosis treatment results in Italy: comparison of the culture- versus the smearbased methods. Eur Respir J 1999; 13: 900-903.

6. Rieder HL, Watson JM, Raviglione MC, et al. Surveillance of tuberculosis in Europe. Recommendations of a Working Group of the World Health Organization (WHO) and the European Region of the International Union Against Tuberculosis and Lung Disease (IUATLD) for uniform reporting on tuberculosis cases. Eur Respir J 1996; 9: 1097-1104.

7. Styblo K. Tuberculosis control and surveillance. In: Flenley DC, Petty TL, eds. Recent advances in respiratory medicine, number 4 . UK, Churchill Livingstone, 1986; pp. 77-108.

8. Weis SE, Slocum PC, Blais FX, et al. The effect of directly observed therapy on the rates of drug resistance and relapse in tuberculosis. N Engl J Med 1994; 330: 1179-1184.

9. Clancy L, Rieder HL, Enarson DA, Spinaci S. Tuberculosis elimination in the countries of Europe and other industrialized countries. Eur Respir J 1991; 4: $1288-1295$.

\footnotetext{
Acknowledgements. The authors would like to thank R. Centis (Italy), D. Popovac (Yugoslavia), and V. Stojcic (Yugoslavia) for their useful comments on the manuscript.
} 
10. Tala E, Kochi A. Elimination of tuberculosis from Europe and the world. Eur Respir J 1991; 4: 11591160.

11. American Thoracic Society, Centers for Disease Control and Prevention. Targeted tuberculin testing and treatment of latent tuberculosis infection. $\mathrm{Am}$ J Respir Crit Care Med 2000; 161: Suppl. S221-S247.

12. Epidemiologic basis of tuberculosis control. In: Rieder HL, ed. France, International Union Against Tuberculosis and Lung Disease, 1999; pp. 1-162.

13. Swedish Institute for Infectious Disease Control, Swedish Heart Lung Foundation. The Swedish Tuberculosis Index 1998. Tryck, Graphium Print and Distribution, Solna, 2000; pp. 1-38.

14. Swedish Institute for Infectious Disease Control, Swedish Heart Lung Foundation. The Swedish Tuberculosis Index 1999. Tryck, Graphium Print and Distribution, Solna, 2001; pp. 1-33.

15. Lillebaek $\mathrm{T}$, Andersen $\AA \mathrm{B}$, Bauer $\mathrm{J}$, et al. Risk of Mycobacterium tuberculosis transmission in a lowincidence country due to immigration from highincidence areas. J Clin Microbiol 2001; 39: 855-861.

16. EuroTB (InVS/KNCV) and the national coordinators for tuberculosis surveillance in the WHO European Region. Surveillance of tuberculosis in Europe. Report on tuberculosis case notified in 1998. EuroTB 2001; 1-105.

17. World Health Organization. Anti-tuberculosis drug resistance in the world. Report No. 2. World Health Organization Document WHO/CDS/TB/2000.278: 1-117. World Health Organization, Geneva, 2000.

18. World Health Organization. Global tuberculosis control. WHO report 2000. World Health Organization Document WHO/CDS/TB/2000.275: 1-179. World Health Organization, Geneva, 2000.

19. Espinal MA, Laszlo A, Simonsen L, et al. Global trends in resistance to antituberculosis drugs. $N$ Engl J Med 2001; 344: 1294-1303.

20. Raviglione MC, Sudre P, Rieder HL, Spinaci S, Kochi A. Secular trends of tuberculosis in Western Europe. Bull World Health Organ 1993; 71: 297-306.

21. Rieder HL, Zellweger JP, Raviglione MC, Keizer ST, Migliori GB. Tuberculosis control in Europe and international migration. Eur Respir J 1994; 7: 15451553.

22. Migliori GB, Raviglione MC, Schaberg $\mathrm{T}$, et al. Tuberculosis management in Europe. Recommendations of a Task Force of the European Respiratory Society (ERS), the World Health Organisation (WHO) and the International Union against Tuberculosis and Lung Disease (IUATLD) Europe Region. Eur Respir J 1999; 14: 978-992.

23. Styblo K, Meijer J, Sutherland I. The transmission of tubercle bacilli - its trend in a human population. Tuberculosis Surveillance Research Unit Report No. 1. Bull Int Union Tuberc 1969; 42: 1-104.

24. Sudre P, ten Dam G, Kochi A. Tuberculosis: a global overview of the situation today. Bull World Health Organ 1992; 70: 149-159.

25. Zafran N, Heldal E, Pavlovic S, Vuckovic D, Boe J. Why do our patients die of active tuberculosis in the era of effective therapy? Tuber Lung Dis 1994; 75: 329-333.

26. Rowinska-Zakrzewska E, Szopinski J, et al. Tuberculosis in the autopsy material: analysis of 1500 autopsies performed between 1972 and 1991 in the
Institute of Tuberculosis and Chest Diseases, Warsaw, Poland. Tuber Lung Dis 1995; 76: 349-354.

27. Hardie RM, Watson JM. Screening migrants at risk of tuberculosis. BMJ 1993; 307: 1539-1540.

28. Research Committee of the British Thoracic and Tuberculosis Association. A tuberculosis survey in England and Wales 1971; the influence of immigration and country of birth upon notifications. Tubercle 1973; 54: 249-260.

29. Ormerod LP. Tuberculosis screening and prevention in new immigrants 1983-88. Respir Med 1990; 84: 269271.

30. Hejdová E, Trnka L. Incidence of tuberculosis in Romanic ethnic group in the Czech Republic. Stud Pneumol Phthiseol Cechoslov 1992; 58: 417-422.

31. Hawker JI, Bakhshi SS, Ali S, Farrington CP. Ecological analysis of ethnic differences in relation between tuberculosis and poverty. BMJ 1999; 319: 1031-1034.

32. Reyes H, Coninx R. Pitfalls of tuberculosis programmes in prisons. BMJ 1997; 315: 1447-1450.

33. Chaves F, Dronda F, Cave MD, et al. A longitudinal study of transmission of tuberculosis in a large prison population. Am J Respir Crit Care Med 1997; 155: 719-725.

34. Kent RJ, Uttley AHC, Stoker NG, Miller R, Pozniak AL. Transmission of tuberculosis in British centre for patients infected with HIV. BMJ 1994; 309: 639-640.

35. Moro ML, Gori A, Errante I, et al. An outbreak of multidrug-resistant tuberculosis involving HIVinfected patients of two hospitals in Milan, Italy. AIDS 1998; 12: 1095-1102.

36. Di Perri G, Cruciani M, Danzi MC, et al. Nosocomial epidemic of active tuberculosis among HIV-infected patients. Lancet 1989; 2: 1502-1504.

37. Centers for Disease Control and Prevention. Multidrug-resistant tuberculosis outbreak on an HIV ward, Madrid, Spain, 1991-1995. Morb Mortal Wkly Rep 1996; 45: 330-333.

38. Patel KR. Pulmonary tuberculosis in residents of lodging houses, night shelters and common hostels in Glasgow: a 5-year prospective survey. Br J Dis Chest 1985; 79: 60-66.

39. Capewell S, France A, Anderson M, Leitch AG. The diagnosis and management of tuberculosis in common hostel dwellers. Tubercle 1986; 67: 125-131.

40. Ramsden SS, Baur S, El Kabir DJ. Tuberculosis among the central London single homeless. A fouryear retrospective study. J Roy Coll Phys London 1988; 22: 16-17.

41. Antonucci G, Girardi E, Armignacco O, Salmaso S, Ippolito G. Tuberculosis in HIV-infected subjects in Italy: a multicentre study. AIDS 1992; 6: 1007-1013.

42. International Union Against Tuberculosis Committee on Prophylaxis. Efficacy of various durations of isoniazid preventive therapy for tuberculosis: five years of follow-up in the IUAT trial. Bull World Health Organ 1982; 60: 555-564.

43. Veen J. Microepidemics of tuberculosis: the stone-inthe-pond principle. Tuber Lung Dis 1992; 73: 73-76.

44. Ferebee SH. Controlled chemoprophylaxis trials in tuberculosis. A general review. Adv Tuberc Res 1969; 17: 28-106.

45. Yang $\mathrm{ZH}$, De Haas PEW, Wachmann $\mathrm{CH}$, van Soolingen D, van Embden JDA, Andersen A B. Molecular epidemiology of tuberculosis in Denmark in 1992. J Clin Microbiol 1995; 33: 2077-2081. 
46. van Soolingen D, Borgdorff MW, De Haas PEW et al. Molecular epidemiology of tuberculosis in the Netherlands: a nationwide study from 1993 through 1997. J Infect Dis 1999; 180: 726-736.

47. Mackay AD, Cole RB. The problems of tuberculosis in the elderly. Quarterly J Med 1984; 212: 497-510.

48. Ferebee SH, Mount FW, Murray FJ, Livesay VT. A controlled trial of isoniazid prophylaxis in mental institutions. Am Rev Respir Dis 1963; 88: 161-175.

49. Veening GJJ. Long term isoniazid prophylaxis. Controlled trial on INH prophylaxis after recent tuberculin conversion in young adults. Bull Int Union Tuberc 1968; 41: 169-171.

50. Ferebee SH, Mount FW. Tuberculosis morbidity in a controlled trial of the prophylactic use of isoniazid among household contacts. Am Rev Respir Dis 1962; 85: 490-521.

51. Egsmose T, Ang'Awa JOW, Poti SJ. The use of isoniazid among household contacts of open cases of pulmonary tuberculosis. Bull World Health Organ 1965; 33: 419-433.

52. Pape JW, Jean SS, Ho JL, Hafner A, Johnson WD, Jr. Effect of isoniazid prophylaxis on incidence of active tuberculosis and progression of HIV infection. Lancet 1993; 342: 268-272.

53. Whalen CC, Johnson JL, Okwera A, et al. A trial of three regimens to prevent tuberculosis in Ugandan adults infected with the human immunodeficiency virus. $N$ Engl J Med 1997; 337: 801-808.

54. Krebs A, Farer LS, Snider DE, Thompson NJ. Five years of follow-up of the IUAT trial of isoniazid prophylaxis in fibrotic lesions. Bull Int Union Tuberc Lung Dis 1979; 54: 65-69.

55. Migliori GB, Casali L, Nardini S, Spanevello A, Besozzi G, Faravelli B. Evaluation of the impact of guidelines on tuberculosis control in Italy. Monaldi Arch Chest Dis 1996; 51: 204-209.

56. Norwegian Government. Regulations on refund of expenses for important drugs. Ministry of Social Affairs, Oslo, 1996.

57. World Health Organization. Tuberculosis control and medical students. World Health Organization Document WHO/TB/98.236:1-53. World Health Organization, Geneva, 1998.

58. Chemtob D, Weiser S, Yitzhak I, Weiler-Ravell D. Medical anthropology: an important adjunct to international TB control. In: Reichman LB, Hershfield ES, eds. Tuberculosis. A comprehensive international approach. New York Basel, Marcel Dekker Inc., 2000; pp. 745-770.

59. Schwoebel V, Lambregts-van Weezenbeek CSB, Moro ML, et al. Standardization of antituberculosis drug resistance surveillance in Europe. Recom mendations of a World Health Organization (WHO) and International Union Against Lung Disease (IUATLD) Working Group. Eur Respir J 2000; 16: 364-371.

60. British Thoracic Association. A controlled trial of six months chemotherapy in pulmonary tuberculosis. First report: results during chemotherapy. $\mathrm{Br} J \mathrm{Dis}$ Chest 1981; 75: 141-153.

61. British Thoracic Association. A controlled trial of six months chemotherapy in pulmonary tuberculosis. Second report: results during the 24 months after the end of chemotherapy. Am Rev Respir Dis 1982; 126: 460-462.

62. World Health Organization. Treatment of tuberculosis: guidelines for national programmes. Second edition 1997. World Health Organization Document WHO/TB/97.220: 1-66. World Health Organization, Geneva, 1997.

63. Iseman MD. Treatment of multidrug-resistant tuberculosis. $N$ Engl J Med 1993; 329: 784-791.

64. Moro ML, Errante I, Infuso A, et al. Effectiveness of infection control measures in controlling a nosocomial outbreak of multidrug-resistant tuberculosis among HIV patients in Italy. Int $J$ Tuberc Lung Dis 2000; 4: 61-68.

65. Gordin F, Chaisson RE, Matts JP, et al. Rifampin and pyrazinamide vs isoniazid for prevention of tuberculosis in HIV-infected patients. An international randomized trial. JAMA 2000; 283: 1445-1450.

66. Tala-Heikkilä M, Tuominen JE, Tala EOJ. Bacillus Calmette-Guérin revaccination questionable with low tuberculosis incidence. Am J Respir Crit Care Med 1998; 157: 1324-1327.

67. Borgdorff MW, Veen J, Kalisvaart NA, Broekmans JF, Nagelkerke NJD. Defaulting from tuberculosis treatment in the Netherlands: rates, risk factors and trend in the period 1993-1997. Eur Respir J 2000; 16: 209-213.

68. Helbling P, Altpeter E, Raeber PA, Pfyffer GE, Zellweger JP. Surveillance of antituberculosis drug resistance in Switzerland 1995-1997: the central link. Eur Respir J 2000; 16: 200-202.

69. Loddenkemper R. The need of antituberculosis drug surveillance in Europe. Eur Respir J 2000; 16: 195-196. 